“C 2010 IEEE. Personal use of this material is permitted. Permission from IEEE must be obtained for all other uses, in any current or future media, including reprinting/republishing this material for advertising or promotional purposes, creating new collective works, for resale or redistribution to servers or lists, or reuse of any copyrighted component of this work in other works.” 


\title{
Electromagnetic Optimal Design of a Linear Induction Motor in linear metro
}

\author{
Wei Xu, Member, IEEE, Jianguo Zhu, Senor Member, IEEE, Yongchang Zhang, \\ D. G Dorrell, Senor Member, IEEE, Youguang Guo, Senor Member, IEEE \\ School of Electrical, Mechanical and Mechatronic Systems, University of Technology,Sydney, Australia \\ Email: weixuhappy@ieee.org
}

\begin{abstract}
An improved T-model equivalent circuit of single-sided linear induction machine (SLIM) has been proposed based on one-dimensional air gap flux linkage equations. The model takes longitudinal end and transversal edge effects into consideration as well as primary terminal half-filled slots, secondary back-iron saturation, and skin effect in secondary conductance fleet. In the circuit, several coefficients including longitudinal end effect coefficients $K_{\mathrm{r}}$ and $K_{\mathrm{x}}$, transversal edge effect coefficients $C_{\mathrm{r}}$ and $C_{\mathrm{x}}$, and skin effect coefficient $K_{\mathrm{f}}$ are achieved by using the dummy electric potential method and complex power equivalence between primary and secondary sides. Performance analysis in constant current constant frequency of the intermediate capacity transit system (ICTS) in Canada validates the T-model circuit. Moreover, one optimal design scheme of SLIM applied in the prototype of propulsion system in high temperature superconducting (HTS) maglev transportation has been proposed. According to the practical requirements, efficiency and primary weight are chosen as optimal objective functions. Thrust, efficiency, power factor and other performance indexes are given out in this paper.
\end{abstract}

\section{INTRODUCTION}

Mass transport metro trains driven by a single-sided linear induction motors (SLIM) have been paid more attention by both academia and industry. This arrangement is illustrated in Fig. 1. This drive system has direct propulsive thrust dependent of the friction between wheel and rail, smaller cross-sectional area for requirement of a tunnel, smaller turning radius, larger acceleration, and stronger climbing ability compared with that of rotary induction machine (RIM) [1-9].

The SLIMs have been widely applied in transportation systems, especially in intermediate speed range. By now, there are two typical examples include the high speed surface transport (HSST) developed by Japan, and the linear metro produced by Bombardier company in Canada [11-14]. According to the most recent investigation, there have been more than twenty commercial linear metro lines with more than 400 kilometers in the world, including Vancouver light train in Canada, Kuala Lumpur rapid train in Malaysia, Kennedy air line in America, linear metro in Japan, Guangzhou subway lines 4, 6, 8 and Beijing airport rapid transportation line in China, and so on. Linear metros have great potential market in China because its aforementioned merits which satisfy with some special transportation requirements, such as great hill-climbing capability in Chongqing, a famous mountainous city in south west.

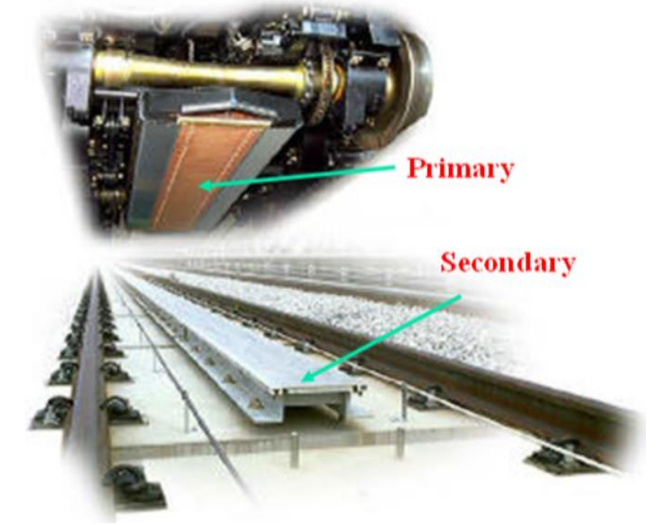

Fig.1 Simple diagram of a linear metro train driven by an SLIM.

In Fig.1, it can be seen that the SLIM primary is hanged below the redirector, which is supplied by a 3-phase inverter on the vehicle. The secondary is flatted on the railway track, which often consists of $3-8 \mathrm{~mm}$ thick copper/aluminum conductance sheet and almost 10-30 mm thick back iron. When the primary three-phase windings are inputted AC current from vehicular converter, they can build up air flux linkage and induce eddy current in the secondary sheet simultaneously. This eddy current will react with aforementioned air gap flux linkage each other so as to produce horizontal electromagnetic thrust that can drive the vehicle forward directly without friction between wheel and track [1-4].

However, the SLIM with its cut-open magnetic circuit, possesses some inherent traits, like longitudinal end-effect, transversal edge-effect and normal force. Furthermore, both ends in the primary just have half-filled slots. These special phenomena will bring nonlinear bad effluences to the air gap flux distribution, and further affect its thrust, power factor, efficiency, et al. How to deduce one comparatively accurate equivalent circuit for steady performance study has been a popular issue in the field of SLIM [3, 4].

By continuous hard working during the past several decades, many models and techniques of SLIM have been proposed. However, effective methods on the design scheme of SLIM have not been obtained easily due to influences by longitudinal and transversal end effects, half-filled slots, etc. $[1,2,4-6]$. The selection of electric loading and magnetic loading is so difficult that one cannot calculate the apparent power (kVA) easily for its strong nonlinear traits. Moreover, the power factor and efficiency are affected by the end effect 
which is again affected by the design technique of SLIM. The pole pitch can be varied structurally and the selection of frequency and rated slip is not easy with the decision on the rated velocity $[7,8]$.

A new improved model is set out in this paper based on the air-gap flux density equation, which fully takes into account longitudinal end and transversal edge effects, half-filled slots, back-iron saturation and skin effect. Then, performance study of one drive machine has been carried out. Furthermore, several optimal design equations for achieving the maximum efficiency and minimum primary weight required by the practical engineering projects are built up, which are nonlinearly constrained functions. It is necessary to choose a suitable solving method to obtain the independent variables, such as the rated slip, number of poles, pole pitch, stack height, ratio of slot width to slot pitch, thickness of secondary conductor sheet, tooth magnetic density, and secondary overhang [9].

\section{THE PHySiCAL MOdEL PhySiCAL STRUCTURE AND MATHEMATICAL ANALYTIC MODEL}

In order to simplify the derivation, some assumptions are proposed in the following [1-9]:

(a) The stator iron has infinite permeability. The material of stator iron is silicon-steel sheet with 0.5 or $0.2 \mathrm{~mm}$ thickness, whose permeability is about 2000 times that of air gap or larger, so in most cases, the permeability of stator iron can be considered infinite.

(b) Winding space harmonics are negligible. Winding space harmonics is related with the primary winding distribution, which can be reduced by optimal winding arrangement during the electromagnetic design procedure. Furthermore, it can be further reduced by relative harmonics elimination control schemes.

(c) The primary and secondary currents flow in infinitesimally thin sheets. By field theories of electrical machine, the winding current or eddy current can be usually represented by current sheets without thickness. The primary or secondary eddy current is of actually discrete quantity, while the current sheet is continuous. If they can produce the same magnetomotive force, they will be equivalent to each other.

(d) All magnetic variables are sinusoidal time functions.

Strictly speaking, the SLIM air gap flux density is one function of $\mathrm{x}-, \mathrm{y}-, \mathrm{z}-$ coordinates, which should be threedimensional model. In the two-dimensional model, the flux density has variation in $\mathrm{x}$ - and $\mathrm{y}$ - coordinates. However, for both two- and three- dimensional models, the equation derivation becomes more difficult, and the calculation procedure is more time consuming. Actually, in many applications, such as linear metro, one-dimensional model only considering the $\mathrm{x}$-axis field variation is sufficient for the engineering requirement. The analytical model with onedimension is shown in Fig. 2, where primary is named as

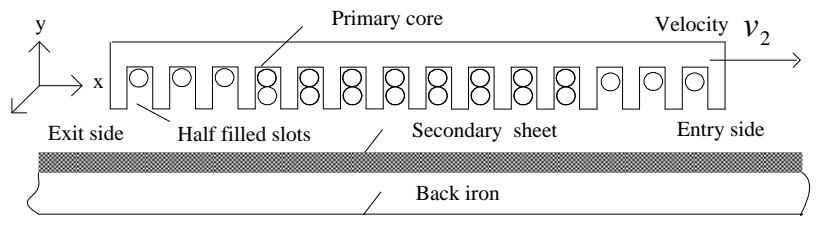

(a)

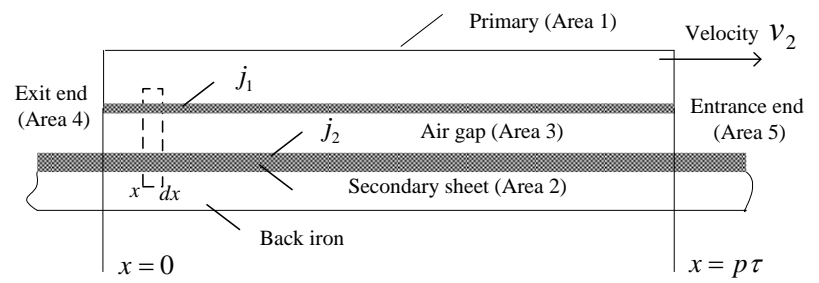

(b)

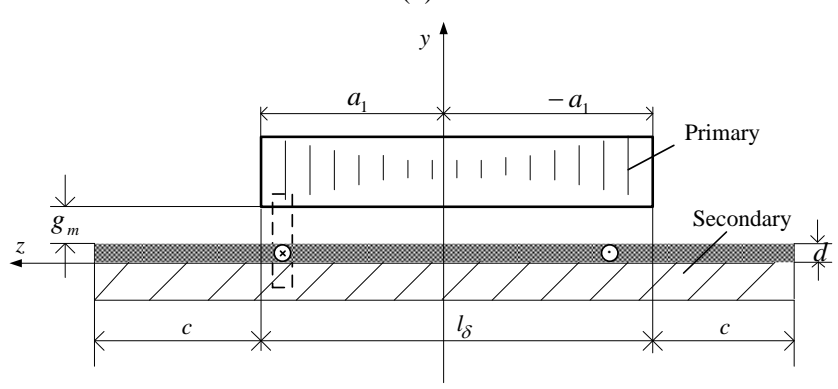

(c)

Fig. 2. The structure and one-dimensional analytical model of SLIM. (a) Physical structure. (b) Longitudinal side view. (c) Transversal side view.

Area 1, secondary sheet Area 2, air gap Area 3, exit end Area 4, and entrance end Area 5.

For special structures, SLIMs have longitudinal end effects resulted from cut-open primary terminals, and transversal edge effects by different width between primary and secondary. Their influences on SLIM parameters can be analyzed separately, and then be gathered up by superposition theorem. More details of the derivations can be found in [4] and [6]. Some important expressions can be summarized as follows.

The skin effect correction coefficient $K_{\mathrm{f}}$ is

$$
K_{\mathrm{f}}=\frac{1+B_{1}^{2} \sinh ^{2}\left(2 K g_{e}\right)}{A_{1}\left[1+B_{1}^{2} \sinh ^{2}(2 K d)\right]}
$$

where $K$ is the function of slip and machine structure parameters, $d$ is the thickness of secondary metal sheet, $g_{\mathrm{e}}$ is the equivalent magnetic air gap length, and $A_{1}$ and $B_{1}$ are coefficients which are affected by slip and machine structure parameters, such as stator pole width/height. $g_{\mathrm{e}}$ can be expressed as

$$
g_{e}=K_{c} K_{u}\left(g_{m}+d\right)
$$

where $K_{c}$ is the Carter coefficient and $K_{u}$ is the magnetic saturation coefficient. $A_{1}$ and $B_{1}$ are derived as

$$
\begin{aligned}
& A_{1}=\cosh ^{2}\left(K g_{e}\right)+\left[\frac{K \rho_{\text {second }} \sinh \left(K g_{e}\right)}{s \omega \mu_{0} d}\right]^{2} \\
& B_{1}=\frac{s \omega \mu_{0} d}{2 K \rho_{\text {second }}}\left[1+\frac{K \rho_{\text {second }}}{s \omega \mu_{0} d}\right]^{2}
\end{aligned}
$$


where $s$ is the slip, $\omega$ is the primary electrical angular velocity, $\rho_{\text {second }}$ is the resistivity of secondary electrical sheet, and $\mu_{0}$ is the permeability of air.

The longitudinal end-effect coefficients $K_{r}$ and $K_{x}$ are denoted by

$$
\begin{aligned}
& K_{r}=\frac{s G}{2 P_{e} \tau \sqrt{1+(s G)^{2}}} \frac{C_{1}^{2}+C_{2}^{2}}{C_{1}} \\
& K_{x}=\frac{1}{2 P_{e} \tau \sqrt{1+(s G)^{2}}} \frac{C_{1}^{2}+C_{2}^{2}}{C_{2}}
\end{aligned}
$$

where $C_{1}$ and $C_{2}$ are the functions of slip $s$ and goodness factor $G, P_{\mathrm{e}}$ is the number of equivalent pole pairs, and $\tau$ is the pole pitch.

The transversal end-effect coefficients $C_{r}$ and $C_{x}$ are illustrated by

$$
\begin{aligned}
C_{r} & =\frac{s G\left[\mathrm{R}_{e}^{2}[T]+\mathrm{I}_{m}^{2}[T]\right]}{\mathrm{R}_{\mathrm{e}}[T]} \\
C_{x} & =\frac{\mathrm{R}_{e}^{2}[T]+\mathrm{I}_{m}^{2}[T]}{\mathrm{I}_{\mathrm{m}}[T]}
\end{aligned}
$$

where $T$ is the function of slip, goodness factor and motor structure, and $\mathrm{R}_{\mathrm{e}}$ and $\mathrm{I}_{\mathrm{m}}$ are the real part and image part of complex $T$, respectively. $T$ is expressed by

$$
T=j\left[\gamma^{2}+\left(1-\gamma^{2}\right) \frac{\lambda}{a_{1} \alpha} \tanh \left(a_{1} \alpha\right)\right]
$$

where $a_{1}$ is half the primary lamination width, $\alpha$ is the ratio of $c$ to $\tau$, and $c$ is half the width of the secondary sheet overhang. $\gamma$ and $\lambda$ can be obtained by

$$
\begin{aligned}
& \lambda=\frac{1}{1+\frac{1}{\gamma} \tanh \left(a_{1} \alpha\right) \tanh \left[K\left(c_{2}-a_{1}\right)\right]} \\
& \gamma^{2}=\frac{1}{1+j s G}
\end{aligned}
$$

where $c_{2}$ is half width of the secondary sheet. The six parameters in the T-circuit: primary resistance $R_{\mathrm{s}}$, primary leakage inductance $L_{\mathrm{ls}}$, secondary equivalent resistance $R_{\mathrm{r}}$, secondary leakage inductance $L_{\mathrm{lr}}$, mutual inductance $L_{\mathrm{m} 1}$, and the iron loss resistance $R_{\mathrm{Fe}}$ in series with the mutual inductance are derived below.

The primary resistance $R_{\mathrm{S}}$ is

$$
R_{s}=\rho_{c u} \times 2 l_{a v} W_{1} / S_{c u}
$$

where $\rho_{C u}$ is the resistivity of copper, $l_{a v}$ is half the average length of the primary winding loop, $W_{1}$ is the number of turns of the primary winding in series, and $S_{c u}$ is the cross sectional area of the primary winding conductor.

The primary leakage inductance $L_{\mathrm{ls}}$ is

$$
L_{l s}=0.025 W_{1}^{2} \frac{l_{\delta}}{q}\left(\frac{\lambda_{s}}{P}+\frac{\lambda_{t}+\lambda_{e}+\lambda_{d}}{P_{e}}\right)
$$

where $l_{\delta}$ is the width of primary lamination, $P$ is the number of actual pole pairs, $\lambda_{\mathrm{s}}$ is the primary slot leakage magnetic conductance, $\lambda_{\mathrm{t}}$ is primary teeth leakage magnetic conductance, $\lambda_{\mathrm{e}}$ is primary winding end leakage magnetic conductance, $\lambda_{\mathrm{d}}$ is primary harmonic leakage magnetic conductance.

The secondary resistance is composed of those of conducting sheet and back iron because the flux can penetrate through the aluminum or copper sheet $[2,6]$, and then enter the back iron. The depth of flux density into back iron $d_{F e}$ is

$$
d_{F e}=\sqrt{\frac{2 \rho_{F e}}{\omega \mu_{F e}}}
$$

where $\rho_{\mathrm{Fe}}$ is back iron resistivity, $\mu_{\mathrm{Fe}}$ is the permeability of back iron. The resistance of secondary conducting sheet $R_{2 \text { sheet }}$ is

$$
R_{2 \text { sheet }}=4 m_{1} \rho_{\text {sec } \text { ond }} \frac{\left(W_{1} K_{W 1}\right)^{2}}{2 P_{e}} \frac{l_{\delta}}{d \tau}
$$

where $m_{1}$ is the number of primary winding phases, $\rho_{\text {second }}$ is the resistivity of the secondary electric sheet, and $K_{\mathrm{w} 1}$ is primary winding coefficient.

The resistance of secondary back iron $R_{2 \text { back }}$ is

$$
R_{2 \text { back }}=4 m_{1} \rho_{F e} \frac{\left(W_{1} K_{W 1}\right)^{2}}{2 P_{e}} \frac{l_{\delta}}{d_{F e} \tau}
$$

Therefore, the secondary equivalent resistance $R_{\mathrm{r}}$ is

$$
R_{r}=\frac{R_{2 \text { sheet }} R_{2 \text { back }}}{R_{2 \text { sheet }}+R_{2 \text { back }}}
$$

The secondary leakage inductance $L_{\mathrm{lr}}$ is

$$
L_{l r}=K_{f} \frac{R_{r}}{2 \pi s f_{1}} B_{1} \sinh (2 K d)
$$

where $f_{1}$ is primary excitation frequency.

The exciting reaction is

$$
L_{m 1}=m_{1} \mu_{0}\left(W_{1} K_{W_{1}}\right)^{2} \frac{l_{\delta} V_{s}}{\pi^{2} f_{1} g_{e} P_{e}}
$$

where $V_{\mathrm{s}}$ is the synchronous velocity of primary side.

The iron loss power $P_{\mathrm{Fe}}$ in SLIM is mainly composed of primary yoke, primary tooth, and secondary back iron losses. They can be estimated by the empirical formulas [6], and then the iron loss resistance $R_{\mathrm{Fe}}$ is calculated by

$$
R_{\mathrm{Fe}}=P_{\mathrm{Fe}} / I_{e}^{2}
$$

where $I_{\mathrm{e}}$ is the excited current.

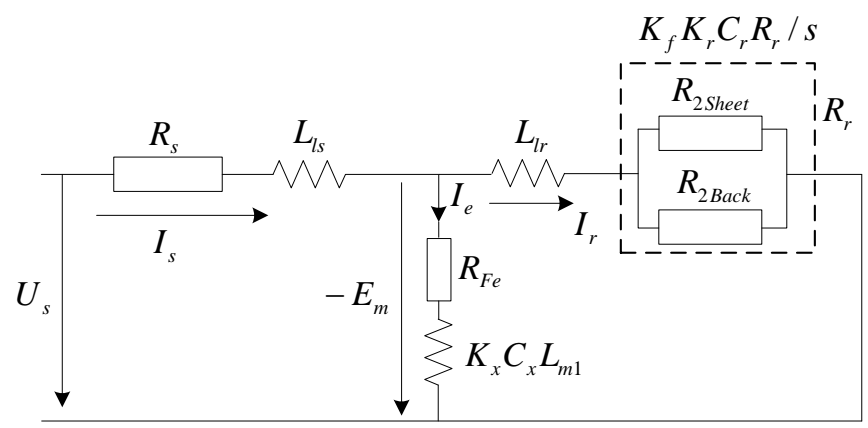

Fig. 3. SLIM T-model equivalent circuit with the back iron resistance.

Based on the T-model equivalent circuit of RIM, the deduced T-model one of SLIM can be seen in Fig. 3, which includes mainly six parameters, i.e. primary resistance, primary leakage inductance, mutual inductance, iron loss 
resistance, secondary leakage, and secondary resistance. The influences from longitudinal end and transversal edge effects can be considered to rectify mutual inductance and secondary equivalent resistance. If suppose $K_{\mathrm{r}}=K_{\mathrm{x}}=C_{\mathrm{r}}=C_{\mathrm{x}}=1$, i.e. neglecting both longitudinal and transversal end effects, the circuit can be simplified as the same as that of RIM. Hence, it is very convenient to analyze the performance of SLIM in the similar way as that of RIM based on the circuit. The curves of mutual inductance and secondary equivalent resistance can be mainly described by the four coefficients.

III. VERIFICATION OF THE T-MODEL CIRCUIT

TABLE I THRUST AND PRIMARY VOLTAGE IN CONSTANT CURRENT AND FREQUENCY

\begin{tabular}{|c|c|c|c|c|c|}
\hline \multicolumn{2}{|c|}{ Item } & \multicolumn{2}{|c|}{$F_{\mathrm{t}}(\mathrm{kN})$} & \multicolumn{2}{|c|}{$U_{\mathrm{s}}(\mathrm{V})$} \\
\hline $\begin{array}{c}f_{1} \\
(\mathrm{~Hz})\end{array}$ & $\begin{array}{c}v_{2} \\
(\mathrm{~m} / \mathrm{s})\end{array}$ & $\begin{array}{c}T- \\
\text { model }\end{array}$ & Measured & $\begin{array}{c}T- \\
\text { model }\end{array}$ & Measured \\
\hline \multirow{5}{*}{10} & 1.00 & 10.29 & 10.6 & 80.69 & 81.00 \\
\hline & 2.00 & 11.31 & 11 & 89.26 & 86.00 \\
\hline & 3.00 & 11.48 & 12.5 & 98.74 & 101.00 \\
\hline & 4.00 & 9.42 & 11.60 & 105.10 & 117.00 \\
\hline & 5.00 & - & - & 106.50 & 128.00 \\
\hline \multirow{7}{*}{20} & 4.00 & 7.50 & 7.80 & 118.50 & - \\
\hline & 5.00 & 8.17 & 8.80 & 126.60 & 123.00 \\
\hline & 6.00 & 8.92 & 9.00 & 136.80 & 137.00 \\
\hline & 7.00 & 9.66 & 9.70 & 150.00 & 145.00 \\
\hline & 8.00 & 10.14 & 11.10 & 166.20 & 169.00 \\
\hline & 9.00 & 9.48 & 11.00 & 182.70 & 194.00 \\
\hline & 10.00 & 6.97 & 8.20 & 192.00 & 220.00 \\
\hline \multirow{6}{*}{30} & 10.00 & 7.26 & 7.20 & 174.60 & - \\
\hline & 11.00 & 7.79 & 8.00 & 186.70 & 183.00 \\
\hline & 12.00 & 8.34 & 8.50 & 201.80 & 195.00 \\
\hline & 13.00 & 8.78 & 9.30 & 221.40 & 218.00 \\
\hline & 14.00 & 8.40 & 9.60 & 242.10 & 246.00 \\
\hline & 15.00 & 6.75 & 7.80 & 255.30 & 277.00 \\
\hline \multirow{8}{*}{40} & 14.00 & 6.10 & 6.20 & 208.70 & 202.00 \\
\hline & 15.00 & 6.46 & 6.60 & 219.40 & 218.00 \\
\hline & 16.00 & 6.88 & - & 232.00 & 232.00 \\
\hline & 17.00 & 7.41 & 7.90 & 249.00 & 252.00 \\
\hline & 18.00 & 7.71 & 8.50 & 270.80 & 269.00 \\
\hline & 19.00 & 7.23 & 7.80 & 291.00 & 300.00 \\
\hline & 20.00 & 5.99 & 7.00 & 303.70 & 330.00 \\
\hline & 21.00 & 4.40 & 5.00 & - & - \\
\hline $\begin{array}{c}\text { Error } \\
(\%)\end{array}$ & - & \multicolumn{2}{|c|}{7.18} & \multicolumn{2}{|c|}{4.06} \\
\hline
\end{tabular}

In order to inspect and verify the T-model equivalent circuit, the steady performance analysis of Intermediate
Capacity Transit System (ICTS) in Canada has been made. The machine structure parameters in details can be found in [7] and [8]. Primary frequency $f_{1}$ varies from $10 \mathrm{~Hz}$ to $40 \mathrm{~Hz}$, and the primary RMS current is kept constant $465 \mathrm{~A}$. The calculated thrust $F_{\mathrm{t}}$ and phase voltage $U_{\mathrm{s}}$ agree with those measured quite reasonably, whose average errors are $7.18 \%$ and $4.16 \%$ respectively.

\section{OPTIMAL DESIGN OF SLIM}

As an example, this paper does optimal design on an SLIM drive for a prototype transportation system, which is levitated by the interaction force between high temperature superconducting (HTS) bulks placed on the ground and permanent magnets (PMs) mounted on the bottom of the vehicle, while the driving force is provided by an SLIM system on the side of the prototype vehicle. Fig. 4 shows the side view of the stationary part of the LIM formed by stacking a number of modular laminated steel cores along the moving direction. Each modular core consists of a concentrated coil and the coils are connected into three-phase windings and supplied by a varying voltage varying frequency inverter. The slot has a depth of $75 \mathrm{~mm}$ and a width of $25 \mathrm{~mm}$. The width of middle tooth is $50 \mathrm{~mm}$, the width of side tooth is $25 \mathrm{~mm}$, the height of yoke is $25 \mathrm{~mm}$, and the transversal length of the modular core is $100 \mathrm{~mm}$ [9].

According to the practical demanding, a further optimization on original dimensions has been made. The efficiency and primary weight are regarded as objective functions under the given thrust as follows.

$$
\begin{cases}\min & f_{1}(x)=-\eta=-\frac{p_{2}}{p_{1}} \\ \min & f_{2}(x)=G_{\text {teeth }}+G_{\text {york }}+G_{\text {winding }}\end{cases}
$$

where $p_{1}$ is the input active power, $p_{2}$ is the output active power, $G_{\text {teeth }}$ is the primary teeth weight, $G_{\text {york }}$ is the primary yoke weight, and $G_{\text {winding }}$ is the primary winding weight.

The following parameters are selected as the constraint variables, including efficiency $(\eta)$, power factor $(\cos \varphi)$, product of power factor and efficiency $(\eta \cos \varphi)$, flux density in primary tooth $\left(B_{\mathrm{t}}\right)$, primary length $(L)$, primary weight $\left(W_{\mathrm{p}}\right)$, thrust $\left(F_{\mathrm{t}}\right)$, primary phase voltage $\left(U_{s}\right)$, primary phase current $\left(I_{s}\right)$, and primary conductor current density $(J)[6]$.

The other parameters are taken as design variables, such as slip $(s)$, stack height $\left(l_{\delta}\right)$, slot depth $\left(h_{\mathrm{t}}\right)$, slot width $\left(b_{\mathrm{s}}\right)$, primary height $\left(h_{\mathrm{a}}\right)$, pole pitch $(\tau)$, short pitch factor $(\beta)$, and number of turns per phase in series $\left(N_{\mathrm{s}}\right)$ [6]. The parameters involving subscript " 0 " are original ones, and the remaining are the optimal results.

The constraint conditions are given by

$$
\begin{aligned}
& g_{1}(x)=\left(\eta_{0}-\eta\right) / \eta_{0} \leq 0 \\
& g_{2}(x)=\left(\cos \varphi_{0}-\cos \varphi\right) / \cos \varphi_{0} \leq 0 \\
& g_{3}(x)=\left(\eta_{0} \cos \varphi_{0}-\eta \cos \varphi\right) / \eta \cos \varphi \leq 0 \\
& g_{4}(x)=\left(B_{t}-B_{t 0}\right) / B_{t 0} \leq 0 \\
& g_{5}(x)=\left(L-L_{0}\right) / L_{0} \leq 0 \\
& g_{6}(x)=\left(W_{p}-W_{p 0}\right) / W_{p 0} \leq 0
\end{aligned}
$$




$$
\begin{aligned}
& g_{7}(x)=\left(F_{t 0}-F_{t}\right) / F_{t} \leq 0 \\
& g_{9}(x)=\left(U_{s}-U_{s 0}\right) / U_{s} \leq 0 \\
& g_{10}(x)=\left(I-I_{0}\right) / I_{0} \leq 0
\end{aligned}
$$

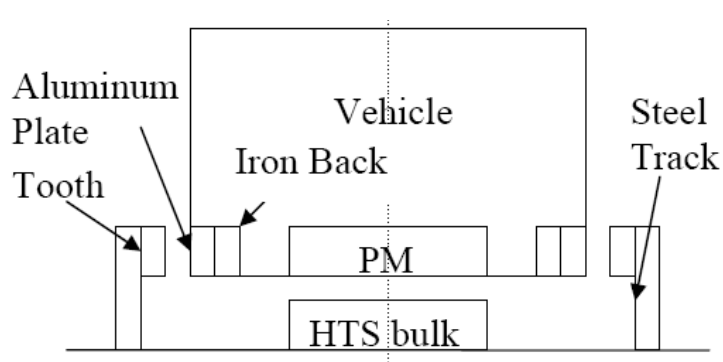

Ground

(a)

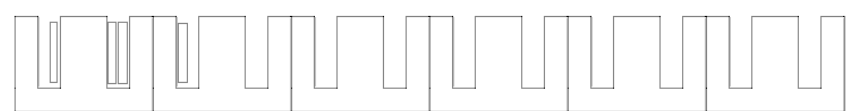

(b)

Fig. 4. Simple diagram of an HTS maglev vehicle with SLIM drive. (a) Schematic diagram of an HTS maglev vehicle with LIM drive. (b). Side view of the stationary part of SLIM.

The above equations (20)-(30) are nonlinear functions influenced by many variables, such as structural parameters and electrical variables. They are solved by both genetic algorithm (GA) and mixture penalty function method. The GA can convert the nonlinear constraint functions into linear sub-problems so as to find a reasonable range of final results very quickly. The mixture penalty function can keep the solutions back to rationale scope by rectification when they are out of the constraint extent [6]. During the optimization process, the rated velocity is set as $40 \mathrm{~km} / \mathrm{h}$.

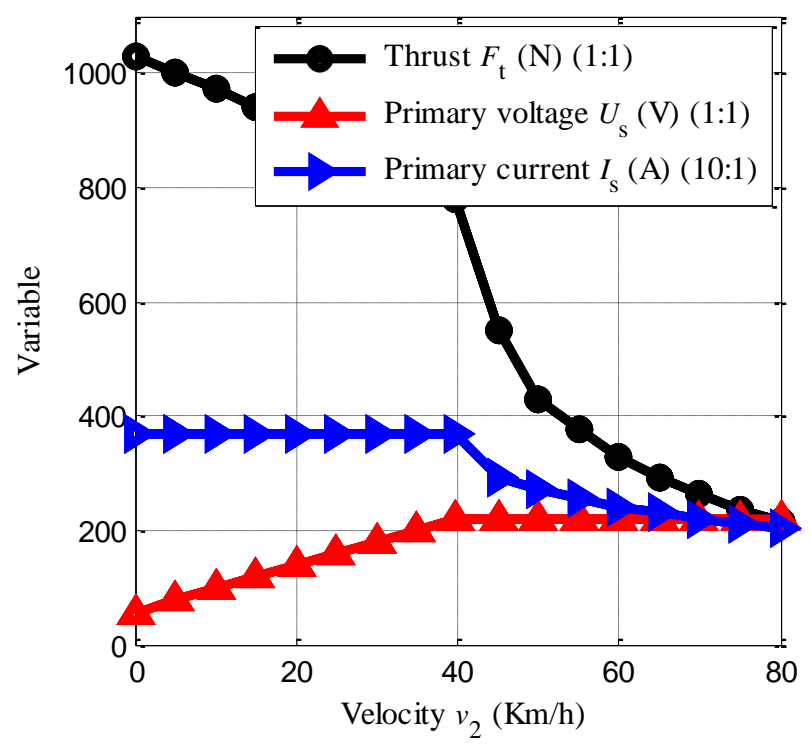

Fig. 5. Thrust, primary voltage and primary current.

The major dimensions and parameters of the proposed LIM include the rated primary voltage of $380 \mathrm{~V}$, rated primary current of $37 \mathrm{~A}$, rated apparent power of $24 \mathrm{kVA}$, rated output power of $8.5 \mathrm{~kW}$, rated driving force of $780 \mathrm{~N}$, vehicle length of $1.65 \mathrm{~m}$, and the mechanical air gap length of $10 \mathrm{~mm}$ [9].

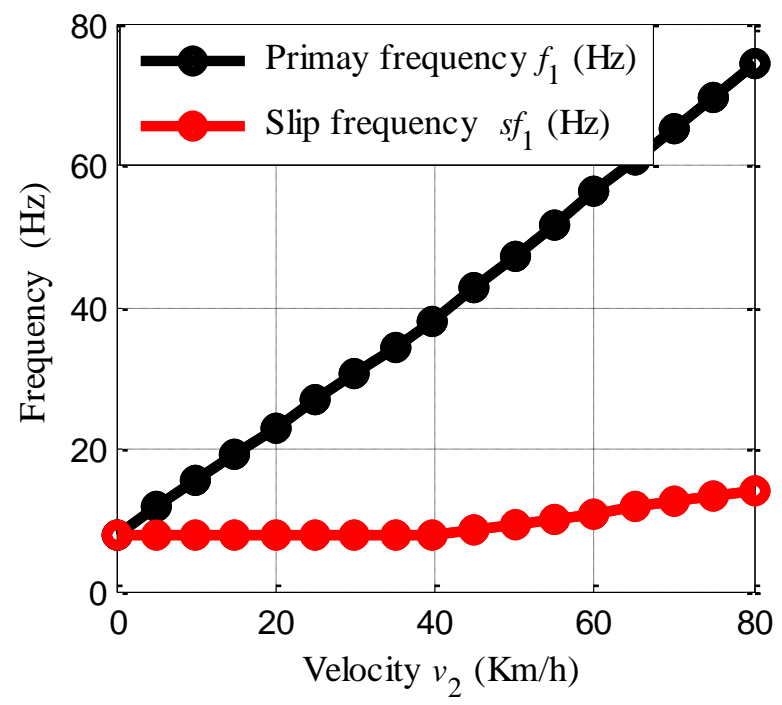

Fig. 6. Primary and slip frequencies.

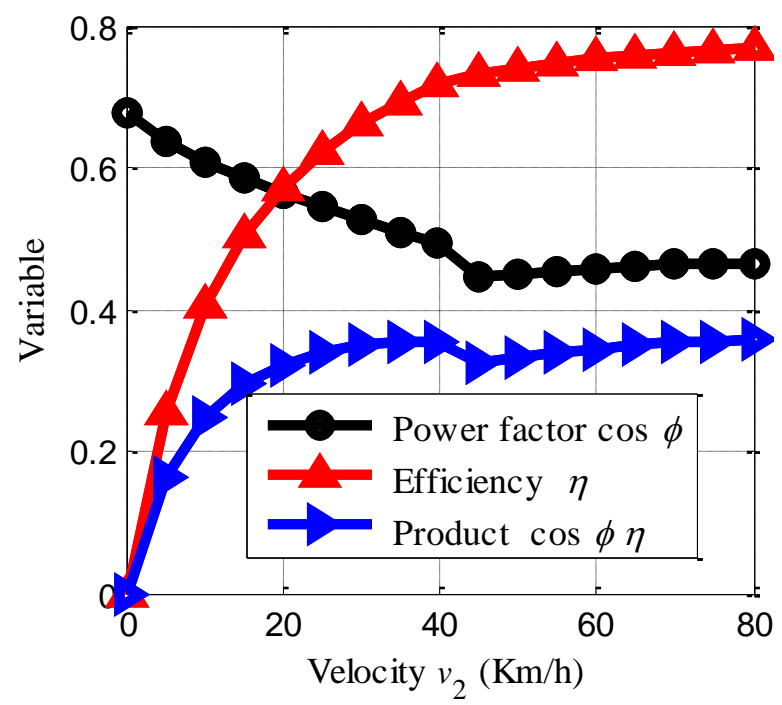

Fig. 7. Power factor, efficiency, and power factor efficiency vesus veclocity.

Based on the equivalent circuit, the major characteristics of LIM can be obtained. For example, the curves of thrust, primary voltage and current versus velocity are shown in Fig. 5. The thrust force is actually determined by the load, i.e. the wind and friction resistances and acceleration. Below the base velocity, the LIM adopts the constant force control so that the thrust force is almost constant. Above the base velocity, the LIM adopts the constant power control so that the output power is almost constant; the phase voltage has reached its maximal value but the reactance continues to increase, so the phase current should be controlled to decrease as well as the thrust.

Fig. 6 illustrates the curves of primary and secondary slip frequencies. Below the base speed, the slip frequency is kept constant, $8 \mathrm{~Hz}$. It could be increased linearly according to 
drive requirement above the base speed for its maximal voltage limitation.

Fig.7 indicates the SLIM drive power factor, efficiency, and product of power factor and efficiency. For the large air gap, the excitation current is a great part of the total phase current, which might constraint the maximal efficiency. By optimization, the maximal efficiency could reach $78 \%$. Fig. 8 is the curves of the corrected mutual inductance and secondary resistance. As the speed goes up, the mutual inductance will decrease and secondary resistance increase for air gap flux density distortion. Fig. 9 plots the drive capacity, input power and output power with respect to vehicle velocity.

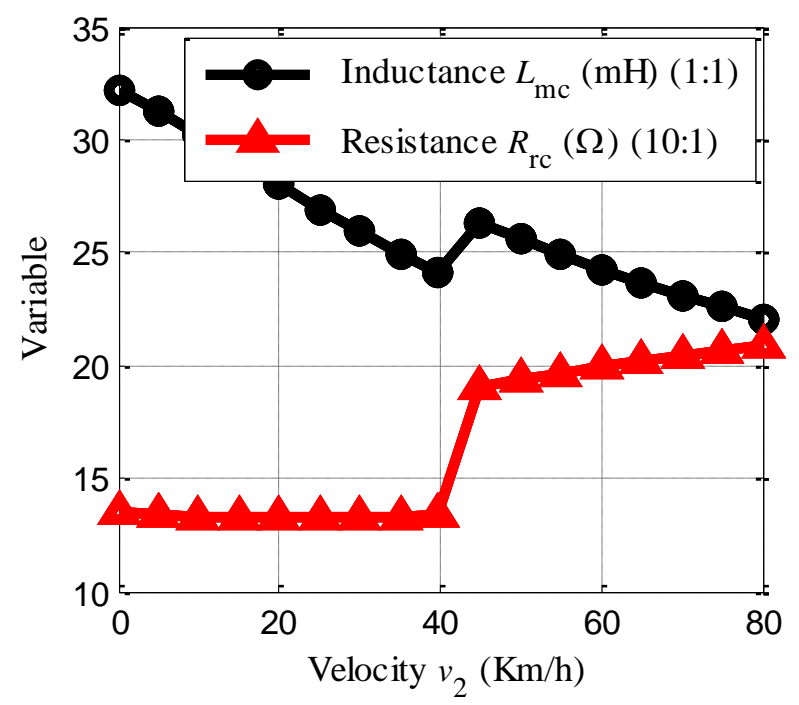

Fig. 8. Corrected mutual inducatance and secondary resistance.

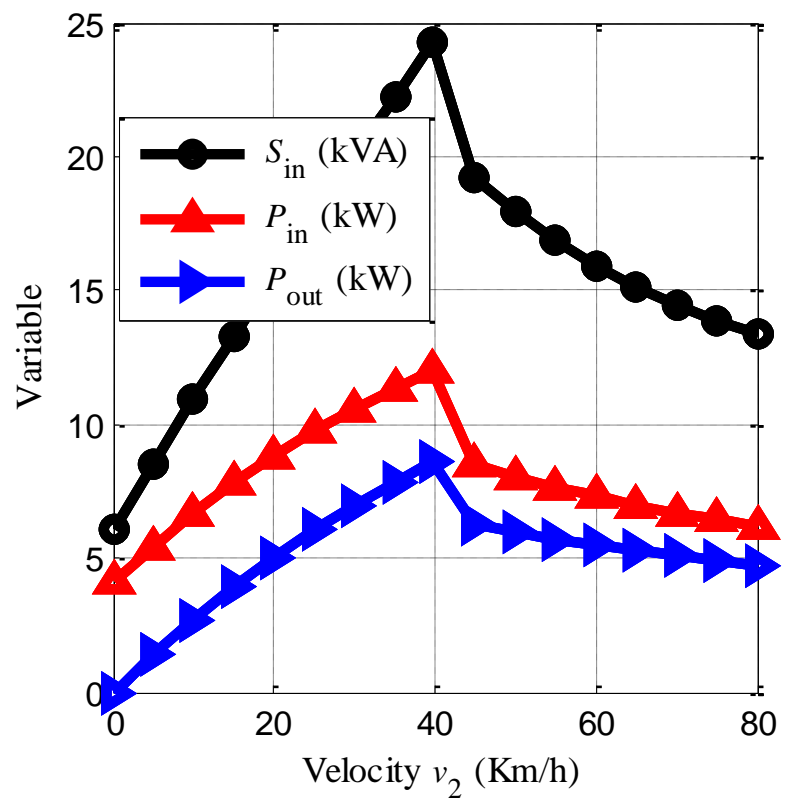

Fig. 9. LIM drive capacity, input power and output power versus velocity.

\section{CONCLUSIONS}

In order to attain high efficiency, the slot width, slot depth and pole pitch are changed greatly in the optimal process. Finally, the ratio of total resistance to reactance becomes smaller, which reduces the power factor. For the limitation of apparent output of converter, restrictions should be made to the product of power factor and efficiency in the new schemes so as to ensure that the optimal results are not worse than the original one. In the linear drive transportation system, the inverter is placed on the vehicle. Under the same output power, the product of power factor and efficiency decides the converter rating power. That is to say, it will affect the weight of converter. Hence, it is significant to improve the efficiency while not decreasing the product of power factor efficiency. In this way, it can ensure the maximum neat load [2].

In the motor design scheme, there are two regions: "constant current" and "constant power". Below the base speed of $40 \mathrm{~km} / \mathrm{h}$, the primary phase current is kept constant (37 A), and the slip frequency is also constant $(8 \mathrm{~Hz})$. Due to power conditioner voltage limit, the constant voltage operation (with phase voltage of $220 \mathrm{~V}$ ) is applied above base speed $[5,8]$. Due to the influence of end effects, the mutual inductance will decrease as the velocity goes up, which could reduce the thrust. It can be seen from Fig.5 that no absolutely constant thrust or constant power region in the SLIM drive system if no compensation for the phase current. Hence, the SLIM drive capability of is not stiff as that of RIM.

In this paper, one maximum efficiency optimal design of SLIM for a propulsion system in maglev transportation is performed. When the number of poles is larger and the pole and slip are smaller, the efficiency will be improved. However, the efficiency is contradictory to power factor. It is necessary to limit the product of power factor and efficiency so as not to increase the inverter weight under the same output power. The prototype will be fabricated as so to verify the optimal electromagnetic design in the next step.

\section{REFERENCES}

[1] W. Xu, J.G. Zhu, et al., "An improved equivalent circuit model of a single-sided linear induction motor," IEEE Trans. Veh. Techno., vol.59, no.5, pp.2277-2289, Jun. 2010.

[2] W. Xu, J.G. Zhu, et al., "Equivalent circuits for single-sided linear induction motors," IEEE Trans. Ind. Appl., 2010, in press.

[3] T. Higuchi and S. Nonaka, "On the design of high efficiency linear induction motors for linear metro," Electrical Engineering in Japan, vol.137, no.2, pp. 36-43, Aug. 2001.

[4] X.L. Long, Theory and magnetic design method of linear induction motor (in Chinese), China: Science Publishing Company, 2006.

[5] W. Xu, Y.H. Li, and G.S. Sun, "Single-sided linear induction motor equivalent circuit model," in Proc. Inter. Sym. Linear Drives for Industrial Applications, Sept. 2007, pp.1-6.

[6] W. Xu, "Research on the performance of single-sided linear induction motor," Ph.D. dissertation, Institute of Electrical Engineering, Chinese Academy of Sciences, China, 2008.

[7] J. Duncan, "Linear induction motor-equivalent-circuit model," Electric Power Applications, IEE Proceedings B, vol. 130,no.1, pp. 51-57, Jan.1983.

[8] J.F. Gieras, Linear induction drives, Oxford: Clarendon press, 1994.

[9] Y.G. Guo, W. Xu, et al., "Design and analysis of a linear induction motor drive for a prototype HTS maglev transportation system," in Proc. Inter. Conf. on Applied Superconductivity and Electromagnetic Devices, Sept. 2009, pp.81-84. 
